\title{
Does rhythmic priming improve grammatical processing in Hungarian-speaking children with and without developmental language disorder?
}

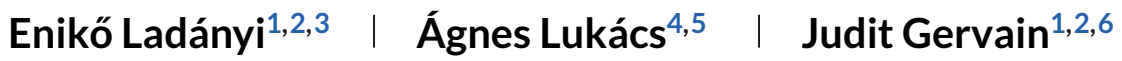

${ }^{1}$ Integrative Neuroscience and Cognition Center (UMR8002), CNRS, Paris, France

${ }^{2}$ Integrative Neuroscience and Cognition Center (UMR8002), Université de Paris, Paris, France

${ }^{3}$ Department of Otolaryngology-Head \& Neck Surgery, Vanderbilt University Medical Center, Nashville, Tennessee, USA

${ }^{4}$ Department of Cognitive Science, Budapest University of Technology and Economics, Budapest, Hungary

${ }^{5}$ MTA-BME Momentum Language Acquisition Research Group, Eötvös Loránd Research Network (ELKH), Budapest, Hungary

${ }^{6}$ Department of Developmental Psychology and Socialization, University of Padua, Padua, Italy

\section{Correspondence}

Enikő Ladányi, Department of

Otolaryngology-Head \& Neck Surgery, Vanderbilt University Medical Center, 1215 21st Avenue South, 10420B Medical Center East, South Tower, Nashville, TN 37232, USA.

Email:enikoladanyi@gmail.com

\section{Funding information}

Marie Sklodowska-Curie, Grant/Award Number: 641858; European Research Council, Consolidator, Grant/Award Number: 773202 (BabyRhythm); Momentum Research Grant of the Hungarian Academy of Sciences, Grant/Award Number: Momentum 96233; National Institutes of Health, Grant/Award Numbers: DP2HD098859, R01DC016977

\begin{abstract}
Research has described several features shared between musical rhythm and speech or language, and experimental studies consistently show associations between performance on tasks in the two domains as well as impaired rhythm processing in children with language disorders. Motivated by these results, in the current study our first aim was to explore whether a short exposure to a regular musical rhythm (i.e., rhythmic priming) can improve subsequent grammatical processing in preschoolaged Hungarian-speaking children with and without developmental language disorder (DLD). Second, we investigated whether rhythmic priming is specific to grammar processing by assessing priming in two additional domains: a linguistic but nongrammatical task (picture naming) and a non-linguistic task (nonverbal Stroop task). Third, to confirm that the rhythmic priming effect originates from the facilitating effect of the regular rhythm and not the negative effect of the control condition, we added a third condition, silence, for all the three tasks. Both groups of children showed better performance on the grammaticality judgment task in the regular compared to both the irregular and the silent conditions but no such effect appeared in the non-grammatical and non-linguistic tasks. These results suggest that (1) rhythmic priming can improve grammatical processing in Hungarian, a language with complex morphosyntax, both in children with and without DLD, (2) the effect is specific to grammar and (3) is a result of the facilitating effect of the regular rhythm. These results could motivate further research about integrating rhythmic priming into traditional speech-language therapy. A video abstract of this article can be viewed at https://youtu.be/zKzGuljZyvU.
\end{abstract}

\section{KEYWORDS}

DLD, grammar, morphology, rhythm, rhythmic priming, SLI

\section{1 | INTRODUCTION}

Speech is inherently rhythmic. This rhythmicity may be central to how we process and comprehend language. Indeed, recent findings suggest that an exposure to musical rhythm may help patients and young children better process spoken language (e.g., Przybylski et al., 2013). These results offer important insights into how we decode speech and language, and open up a promising new avenue of intervention techniques for developmental speech/language disorders. These early findings thus need to be extended and generalized. In this study, we, 
therefore, ask whether rhythmic priming improves language processing in Hungarian-speaking children with typical and atypical language development and we probe whether this effect is specific to grammar or whether it applies more generally to other cognitive domains.

\subsection{Rhythmic priming}

Neural resources for music and language overlap (e.g., Patel et al., 2014; Marie et al, 2011; Kotz \& Schwartze, 2010), and individual differences in rhythm processing have been found to be linked to speech/language skills. Associations have been documented between various measures of musical rhythmic abilities and phonological (Moritz et al., 2013; Ozernov-Palchik et al., 2018; Woodruff Carr et al., 2014) as well as grammatical (Gordon, Jacobs et al., 2015; Gordon, Shivers et al., 2015; Lee et al., 2020; Woodruff Carr et al., 2014) skills.

Can shared neural processes between rhythm and language processing be harnessed for therapeutic purposes? Initial findings of restored neural responses on a grammaticality judgment task after presentation of a regular rhythmic prime in German-speaking patients with basal ganglia injury (Kotz et al., 2005) and Parkinson disease (Kotz \& Gunter, 2015) motivated an intriguing line of studies that are often referred to as rhythmic priming studies.

This work aims to explore whether performance on various linguistic tasks can be improved by a presentation of a rhythmic stimulus with a regular beat immediately before the linguistic task. In the majority of the rhythmic priming studies, participants are exposed to an auditory signal (e.g., sequence of percussion beats) with either a regular or irregular beat/non-rhythmic stimuli before completing a linguistic task. Previous research has found an improved performance on a grammaticality judgment task after presentation of a regular rhythmic prime in French-speaking children with dyslexia (Przybylski et al., 2013) and DLD (Bedoin et al., 2016; Przybylski et al., 2013) as well as in typically developing French-speaking (Bedoin et al., 2016; Fiveash et al., 2020; Przybylski et al., 2013) and English-speaking (Chern et al., 2018) children. The effect was also found in young adults with and without dyslexia who showed a larger ERP response to grammatical violations following regular versus the irregular primes (Canette et al., 2020).

A few studies also focused on rhythmic priming effects on phonological perception in pseudowords (Cason \& Schön, 2012) and sentences (Cason et al., 2015). These studies aimed at investigating the degree to which the acoustic structure of musical rhythmic patterns could act as a scaffold for linguistic processing, and therefore used a slightly different priming paradigm from the grammaticality judgment studies as the rhythm of the primes either matched or did not match the prosodic structure of the speech stimuli. Matching primes facilitated phonological processing compared to not matching primes extending the effect of rhythmic priming to phonemic perception.

These results are highly relevant for our understanding of speech and language processing, and they also hold the promise of providing new intervention methods for speech and language disorders. However, this field is still new. The exact nature of the effect and the underlying mechanisms are not fully understood, so further empirical work

\section{Research Highlights}

- Six-year-old Hungarian-speaking children with and without developmental language disorder (DLD) perform better on a grammar task subsequent to exposure to a regular rhythm versus an irregular rhythm/silence

- The effect of regular rhythm is specific: it improves performance on a grammatical task but not on a word retrieval or a non-linguistic task

- Difference between performance following regular versus irregular rhythm originates from the facilitating effect of the regular rhythm (not the negative effect of the irregular rhythm)

- The results highlight the importance of rhythm in spoken language processing, and point towards a possible intervention tool in language disorders

is necessary to explore and better document them. The aim of the current study is to contribute to a better characterization of the rhythmic priming effect in at least three ways.

First, while several studies tested the effect of rhythmic priming on grammar and phonological processing, we are not aware of any studies exploring the phenomenon in other linguistic domains. Only one study tested the question with non-linguistic tasks (Chern et al., 2018) finding no effect of rhythmic priming suggesting a domain-specific effect for language. The non-linguistic tasks used in that study, however, differed considerably from the grammar task in several respects such as the number of blocks, number of trials within the blocks or the way how trials were presented. Exploring and documenting rhythmic priming in other non-linguistic as well as linguistic but non-grammatical tasks is important for learning more about the origin of the rhythmic priming effect and the therapeutic contexts within which it can be used. One aim of the current study is, therefore, to explore the scope of the effect.

Second, previous work tested rhythmic priming comparing performance following regular primes with performance following either an irregular prime (Chern et al., 2018; Przybylski et al., 2013) or a nonrhythmic baseline condition (Bedoin et al., 2016). Although all these studies have shown a rhythmic priming effect, the contribution of the facilitative effect of the regular prime and the negative effect of the irregular prime cannot be disentangled with using two conditions. With a design including only a regular and an irregular condition, it is impossible to determine if the effect appears because regular rhythm facilitates grammar performance or because irregular rhythm has a negative effect. If rhythmic priming appears when comparing performance following a regular rhythm to silence, that suggests that the regular rhythm has a facilitating effect. However, it remains to be determined whether rhythmic priming can be accounted for by only the positive effect of the regular prime, or by the combination of the positive effect of the regular prime and the negative effect of the irregular prime. To answer this question, the current study used a regular, an irregular and a non-rhythmic baseline condition within the same paradigm. 
Third, the rhythmic priming effect has so far only been investigated in a few languages (French, English, German), all of which belong to the Indo-European language family and, albeit rhythmically different, have comparable morphosyntactic structure. To test whether rhythmic priming is a language-general phenomenon, it is crucial to test it in languages with various features. In addition, due to its highly complex morphosyntax (see next section), the gap between typically and atypically developing children's grammatical abilities is greater and more readily observable in Hungarian than in morphologically poor languages. Hungarian thus offers an ideal testing ground to explore the magnitude and potential clinical relevance of the rhythmic priming effect.

\subsection{The importance of investigating rhythmic priming in Hungarian}

Hungarian is an agglutinative language belonging to the Uralic/FinnoUgric language family. Word order is relatively free, and grammatical relations are mainly expressed by suffixes. Both verbal and nominal morphology is complex. For instance, verbs agree with the number and person of their subject as well as with the definiteness of the object. Tense and mood are also marked. These features result in a large number of possible forms showing high complexity. For instance, olvashatnád ("you may/could read it") consists of the word stem olvas ("read"), the modal suffix -hat and the 2nd person singular definite verb suffix in present tense and conditional mood (-nád). In addition, both stems and suffixes show strong allophonic variation, for example, as a result of vowel harmony. Lexical stress in Hungarian is also different from lexical stress in the languages in which rhythmic priming was studied before. Hungarian has fixed stress on the first syllable of words (Siptár \& Törkenczy, 2000), which thus provides a cue to word boundaries and lexical retrieval. The speech rhythm of Hungarian is syllable-timed, similarly to French, but unlike that of English and German.

Previous studies with children tested the effect of rhythmic priming on the processing of suffixes in English and French. These languages have a simpler morphological system than Hungarian. It is possible that exposure to a regular rhythm is sufficient to boost morphological processing in languages with a simple morphology but does not have an effect in morphologically complex languages in which a greater variety of suffixes need to be processed, with sometimes multiple suffixes attached to a stem.

For example, in the Chern et al. (2018) study children always had to detect a missing third person singular $-s$ as a number agreement error and a missing past tense -ed as a tense agreement error. English does not allow for a greater diversification of the error types. In contrast, in Hungarian, full verbal conjugation paradigms can be found both in the present and the past tense. In addition, the realization of suffixes differs depending on the phonological features of the word stem. To test how the complexity of the Hungarian verb inflection system interacts with rhythmic priming, in the current study we included all six forms of the verb conjugation paradigm both for present and past tense suffixes as well as verbs with different phonological features leading to a high diversity in the phonetic realization of the grammatical errors to be detected.

\section{3 | Developmental language disorder}

In addition to a better characterization of the rhythmic priming effect in general, we also aim to contribute to the limited amount of research exploring the possibility of integrating rhythmic priming into therapeutic interventions for children with DLD. DLD is a developmental disorder formerly known as Specific Language Impairment (SLI) that primarily affects language (with less prominent problems in other domains). Language problems in children with DLD cannot be attributed to obvious impairments in other cognitive domains or perceptual deficits, neurological disorders, emotional, or social problems, environmental deprivation, or intellectual disability, but the underlying causes of DLD are not well understood yet (Bishop et al., 2017; Leonard, 1998). Traditional accounts suggest a grammar-specific deficit (Clahsen, 1999; Gopnik \& Crago, 1991; van der Lely \& Stollwerck, 1997; Rice et al., 1995), while more recent theories also emphasize the role of domaingeneral problems and their potential contribution to the linguistic problems (Gathercole \& Baddeley, 1990; Hsu \& Bishop, 2011; Leonard, 1998; Tallal \& Piercy, 1973; Ullman \& Pierpont, 2005).

Hungarian-speaking children with DLD show prominent difficulties in morphology. They make mistakes with case markers (Lukács et al., 2009) and other aspects of verb morphology were also found to be impaired (Leonard et al., 2012), as were sentence comprehension and production (Kas \& Lukács, 2008). Impairments were found in the lexical domain as well: vocabulary size was shown to be lower (Vinkler \& Pléh, 1995) and word retrieval was less efficient (Ladányi \& Lukács, 2016) in children with DLD than in their typically developing peers.

Populations with language impairments often show weaker rhythmic skills compared to typically developing children. The Atypical Rhythm Risk Hypothesis posits that individuals with atypical rhythm are at higher risk for developmental speech/language disorders (Ladányi et al., 2020). In particular, several studies have found impaired performance on rhythm-related tasks in children with dyslexia (e.g., Muneaux et al., 2004; Overy et al., 2003) and with DLD (Bedoin et al., 2016; Corriveau \& Goswami, 2009; Corriveau et al., 2007; Cumming et al., 2015). While it is not known yet if rhythm problems are a cause (Goswami, 2011) or simply a frequently co-morbid feature of developmental speech and language problems, Ladányi et al. (2020) hypothesize that potentially shared biological underpinnings between rhythm and multiple facets of speech-language development, at the genetic and/or neural levels, may account for associations between rhythm and language traits observed in the population.

Regardless of the origin of deficits in DLD, prior work in English and French shows rhythmic priming effects in this population (Bedoin et al., 2016; Przybylski et al., 2013), such that grammatical task performance is enhanced by regular musical primes. If further research including randomized controlled trials reveals that rhythmic priming can facilitate traditional language therapy at least in a subgroup of children with DLD, rhythmic priming could be integrated into the battery of therapeutic interventions, even if mechanisms underlying rhythmic priming are yet to be understood. This approach is in line with evidence-based practice (ASHA, 2005), that is prevalent in speech-language therapy and in medicine in general, emphasizing the efficacy of a treatment. 
There is an urgent need to improve treatment for children with DLD (Rosenbaum et al., 2016), as DLD has a relatively high prevalence rate ( 7\%, Tomblin et al., 1997), and without efficient treatment, these individuals develop life-long academic, economic, social, and emotional difficulties (Conti-Ramsden et al., 2018).

\subsection{The current study}

In the current study, we aim to explore three questions: (1) Does the presentation of a regular rhythm improve grammatical processing in Hungarian preschool-aged children with and without Developmental Language Disorder? (2) Is the rhythmic priming effect specific to grammar, general across language domains or general across cognitive domains? (3) Does the rhythmic effect result from the facilitative effect of regular rhythm, the negative effect of the irregular rhythm or both?

Our first aim is to explore the rhythmic priming effect in Hungarianspeaking children with TD and DLD. Previous studies found a rhythmic priming effect in a few languages (French, English, German) both in individuals with and without language disorders. It is important to document, however, if the effect is present in various languages to explore its generality across languages. Hungarian is a perfect candidate as its morphology and prosody differs considerably from those of previously tested languages. Testing if the effect appears in Hungarian speaking children with DLD, who have particular difficulties with morphology, beyond children with TD is crucial for investigating its potential clinical utility.

Based on our current understanding, rhythmic priming is a phenomenon present across languages. Therefore, we expect that rhythmic priming will facilitate grammar processing in Hungarian. As previous research has shown a rhythmic priming effect not only in TD children but also in children with DLD despite their impaired rhythm processing skills, we do not expect to see a group difference in the rhythmic priming effect.

Our second aim is to explore whether rhythmic priming is domaingeneral, specific to language or specific to the processing of spoken language. To test the specificity of rhythmic priming to language processing, we included a non-linguistic task (non-verbal Stroop task) to our design complementing the grammaticality judgment task. We aimed to match the procedures of our non-grammatical tasks in every possible respect to the grammaticality judgment task. Furthermore, similarly to Chern et al. (2018)'s study, we chose a task that requires attentional processes but stimuli do not involve regularities as speech or rhythm does.

In addition to the non-linguistic task, we also included a linguistic but non-grammatical task to our design to examine the possibility that rhythmic priming is not domain-general but is also present in language production beyond language processing.

We do not expect to find a rhythmic priming effect in the nonlinguistic control task. As no studies have tested the effect of rhythmic priming on a linguistic but non-grammatical task yet, it is less clear if rhythmic priming can affect word retrieval. The presence of a rhythmic priming effect in the picture naming paradigm would indicate that the effect appears due to shared processes between rhythm and language in general while a lack of a rhythmic priming would suggest its specificity to grammar or spoken language processing.

Our third aim is to better understand the origin of the rhythmic priming effect by comparing performance in three within-subject conditions: one in which a regular rhythm is used as a prime, one with an irregular rhythm and a baseline condition in which children were not presented with any auditory stimuli. Previous studies compared performance only between two conditions (regular vs. irregular: Chern et al., 2018; Przybylski et al., 2013; regular vs. non-rhythmic baseline condition: Bedoin et al., 2016), which did not allow for a direct comparison of the irregular prime to a non-rhythmic baseline condition. By including three conditions, we expect to better understand whether regular rhythm improves performance, irregular rhythm hinders it or rhythmic priming results from the combination of the positive effect of the regular prime and the negative effect of the irregular prime.

We expect to find better performance following the regular prime than following the irregular prime and the baseline condition. As Bedoin et al. (2016) discusses, the effect size of the difference between the regular and the irregular condition was larger in Przybylski et al.'s (2013) study than between the regular and the non-rhythmic baseline conditions in their study, suggesting that the irregular prime may have a negative effect on grammatical processing. Based on this observation, we expect to find weaker performance in the irregular condition than in the baseline condition.

\section{METHODS}

\section{1 | Participants}

Seventeen 5-7-year-old children with DLD and 17 age- and IQmatched typically developing children participated in the study. Demographic and screening data for the two groups are shown in Table 1. Children were recruited from six different pre-schools in Budapest. As a first step of recruitment, a larger group of children showing language problems was selected by the speech-language therapists of the pre-schools. Children whose parents agreed to participate in the study $(n=50)$ were screened for DLD by a speechlanguage therapist using four language tasks (the Hungarian version of the Peabody Picture Vocabulary Test (Csányi, 1974), the Hungarian adaptation of the Test for Reception of Grammar (Bishop, 1983, 2012; Lukács et al., 2012), the Hungarian Sentence Repetition Test (Magyar Mondatutánmondási Teszt; Kas \& Lukács, in preparation), and a nonword repetition test (Racsmány et al., 2005) as well as a non-verbal intelligence task (Raven Colored Progressive Matrices, Raven et al., 1987)). Children who scored at least 1.5 SDs below age norms on at least two out of the four language tasks and had an IQ above 85 were selected for the DLD group ( $n=17)$. After selecting the DLD group, typically developing children matching in age and sex to children in the DLD group were selected by the teachers in the same pre-schools. Children whose parents agreed to participate in the study completed 
TA B LE 1 Demographic data and results on the screening tests in typically developing children and children with DLD

\begin{tabular}{llll} 
& TD mean (SD) & DLD mean (SD) & difference \\
\hline Age & $74 \mathrm{mo}(6 \mathrm{mo})$ & $74 \mathrm{mo}(6 \mathrm{mo})$ & $\mathrm{t}(16)=1.201$, n.s. \\
IQ (Raven) & $104(10)$ & $102 \mathrm{y}(9)$ & $\mathrm{t}(16)=.890, n . s$. \\
\hline Parental education & $14 \mathrm{y}(1.8 \mathrm{y})$ & $12 \mathrm{y}(1.6 \mathrm{y})$ & $\mathrm{t}(16)=3.267 p=0.005$ \\
\hline PPVT & $82(17)$ & $63(8)$ & $\mathrm{t}(16)=4.258 p=0.001$ \\
\hline TROG & $65(4)$ & $50(11)$ & $\mathrm{t}(16)=6.520 p<0.001$ \\
\hline Sentence repetition & $30(9)$ & $20(9)$ & $\mathrm{t}(16)=3.154 p=0.006$ \\
\hline Non-word repetition & $4.7(0.9)$ & $2.8(1.2)$ & $\mathrm{t}(16)=5.343 p<0.001$ \\
\hline
\end{tabular}

Abbreviations: PPVT, Peabody Picture Vocabulary Test, TROG, Test for Reception of Grammar, DLD, Developmental Language Disorder.

TA B LE 2 Examples of grammatically correct and incorrect sentences in the rhythmic priming grammaticality judgment task

\begin{tabular}{lll} 
& Correct version & Violation \\
Number agreement & $\begin{array}{l}\text { A kisbaba alszik az ágyban. } \\
\text { "The baby is sleeping in the bed." }\end{array}$ & $\begin{array}{l}\text { *A kisbaba alszanak az ágyban. } \\
\text { "The baby are sleeping in the bed." }\end{array}$ \\
\hline Tense & $\begin{array}{l}\text { Tegnap este sok fagyit kaptunk. } \\
\text { "We got a lot of ice-cream last evening" }\end{array}$ & "Tegnap este sok fagyit kapunk. \\
\end{tabular}

the non-verbal intelligence task. One TD child matching in IQ $(<5$ points of difference in IQ), age ( $<3$ months difference) and sex was selected for each DLD child. We made every effort to match the groups in parent education level, but this aim could only partially be met, and the educational level of the DLD group is slightly lower than that of the TD group (see Table 1). TD children also completed the screening tasks to make sure that they did not have language impairment. None of the TD children performed below average on the screening tasks. All children were tested with the informed consent of their parents, in accordance with the principles set out in the Declaration of Helsinki and the stipulations of the local Institutional Review Board.

\section{2 | Tasks}

\subsection{1 | Grammaticality judgment task}

\section{Stimuli}

We created 60 grammatically correct Hungarian sentences. Then we modified these sentences by violating either the number agreement between the verb and the subject or the tense of the verb with respect to the adverb (Table 2). All six forms (singular and plural forms, in 1st, 2nd, and 3rd person) of the present and past verb conjugation paradigm were equally represented both in grammatical and ungrammatical sentences. Two lists of sentences were created by combining 30 grammatically correct and 30 grammatically incorrect sentences. We included correct and incorrect versions of the same sentence in different lists, therefore one child could not hear both (see examples in Table 2), and lists were randomly assigned to children. We also made sure that the two lists were matched in their sentence types and vocabulary. Sentences were recorded by an adult female speaker in a mild childdirected manner.
As regular and irregular primes, we used the same stimuli as several previous studies (Bedoin et al., 2016; Chern et al., 2018; Przybylski et al., 2013). Both sequences were played on a tam-tam and maracas and contained the same number of tones. The regular prime had a rhythmic structure from which it was relatively easy to extract the meter, while it was more difficult to extract the rhythmic structure from the irregular prime (see a more detailed description of the primes in Przybylski et al., 2013).

\section{Design and procedure}

During the grammaticality judgment task, children were presented with six blocks of ten sentences on which they were asked to make grammaticality judgments (see a summary of the task procedures in Figure 1). Each block was preceded by a 32 -s-long prime. Two primes

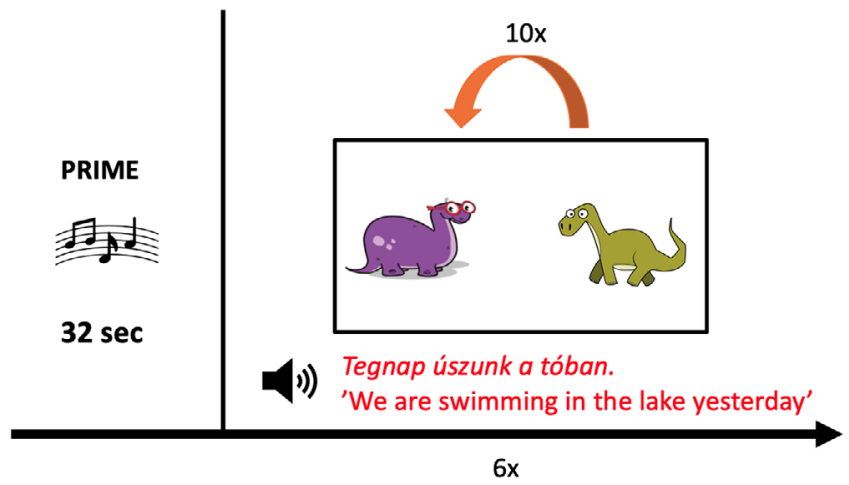

FIGURE 1 Procedures of the grammaticality judgment rhythmic priming task. The grammaticality judgment task consisted of six blocks. In each block, first, children were presented with a prime, and then with 10 sentences half of which was grammatical and the other half was ungrammatical 
belonged to the regular condition, two belonged to the irregular condition and two primes belonged to the baseline condition, which did not contain any auditory stimuli. Prime conditions followed each other in a pseudo-randomized order with the restriction that two primes from the same condition could not follow each other. A picture of a cat relaxing and listening to music was visually presented on the screen while the prime stimuli were played. Children were instructed to relax and take some rest during the primes. Children took breaks of different lengths (from a few seconds to a few minutes) before the presentation of the primes. Sentences were presented immediately after the primes with no breaks.

Each block contained five grammatically correct and five grammatically incorrect sentences, which were presented to the child in a randomized order. The type of violation was counterbalanced across blocks.

We created a background story similar to the one used in previous studies (Bedoin et al., 2016; Chern et al., 2018; Przybylski et al., 2013) to make our task more comprehensible and interesting for young children. Before the task, we introduced them a purple and a green dinosaur. They were informed that the purple dinosaurwhich looked very confident and attentive-was very attentive, so it said everything correctly, while the green dinosaur-which looked somewhat confused-was less attentive, and always made mistakes. We presented them with examples of the sentences the dinosaurs produced. As the first part of the practice phase, children heard the same sentence, once in a correct form, once in an incorrect form, and they had to decide which dinosaur produced the sentence. A second practice phase followed, in which children were presented with different correct and incorrect sentences and they had to decide which dinosaur produced the sentence. Children got feedback for each response during the practice phase. After we made sure that children understood the task, we moved on to the test.

We used d' scores to measure grammaticality judgment performance, similarly to previous studies (Bedoin et al., 2016; Chern et al., 2018; Przybylski et al., 2013). D' is a measure used by signal detection theory that describes the participant's ability to discriminate between two types of stimuli (in the current study between grammatical and ungrammatical stimuli) and was calculated as the difference between the $z$-transformed hit rate and false alarm rate ( $d^{\prime}=z$ (hit rate)- $z$ (false alarm rate)).

We presented stimuli and collected data with OpenSesame (Mathôt et al., 2012) for all the three rhythmic priming tasks.

\subsubsection{Picture naming task}

\section{Stimuli}

Sixty pictures of simple everyday objects that the children likely knew were selected from the picture set used by the norming study of Bates and colleagues (2003). Pictures were grouped into six blocks. The same auditory stimuli were used as primes as in the grammaticality judgment task.

\section{Design and procedure}

To make sure that children were familiar with the names of the pictures, they were asked to name all the pictures in a randomized order at a previous testing session.

The structure of the picture naming task was the same as the structure of the grammaticality judgment task. Children were presented with a prime and then named 10 pictures. Children were asked to name pictures as quickly and as accurately as possible. Pictures were presented in a randomized order within a block and blocks of pictures were randomly assigned to a prime condition. Children's responses were audio-recorded. Naming errors and response times of the correct responses were coded based on the recording. We decided to code naming times off-line for a more accurate measure. Based on our experience with naming studies with young children, automatic measurements detecting the onset of the name are problematic, since children often make false starts, emitting sounds other than the name before actually naming the picture, which activates the voice key. Children also often produce or start to produce names too softly, which fails to activate the voice key. Both of these lead to inaccurate measures (see also Cummings et al., 2016). We excluded incorrect answers and answers with naming times above $5 \mathrm{~s}$, since they indicate that the child was inattentive at that trial, and calculated mean naming times for the three conditions. Accuracy was also coded and calculated, but since performance was at ceiling, we did not analyze accuracy data statistically.

\subsubsection{Non-verbal Stroop task}

Stimuli

For the non-verbal Stroop task, we created arrows appearing on a blank screen. Arrows pointed to the left, to the right, up or down and appeared either in the middle of the screen (baseline condition) or in the left, right, top, or bottom of the screen either in a congruent position with the direction of the arrow (e.g., an arrow pointing up appears at the top of the screen) or in an incongruent position with the direction of the arrow (e.g., an arrow pointing up appears at the bottom of the screen). Six blocks of 20 trials were created. The number of arrows with a congruent, incongruent, and middle position were counterbalanced across blocks as well as the number of arrows pointing to right, left, up, and down.

As primes, we used the same auditory stimuli as in the grammaticality judgment task and the picture naming task.

\section{Design and procedure}

The structure of the task was the same as in the grammaticality judgment task and the picture naming task. Children were presented with a prime and then with a block of 20 arrows. Children were asked to press a button based on the direction of the arrow. Arrows followed each other in a randomized order in each block and associations between arrow blocks and prime conditions were also randomized. The task was preceded by a practice session. We calculated two different measures for the non-verbal Stroop task. First, for testing the effect of rhythmic priming on executive functions, we calculated mean Stroop effects 
TA B LE 3 a-b. (a) Means and standard deviations of hit rates, false alarm rates in the DLD and TD groups in the three rhythm conditions. (b) Means and standard deviations of z-scored hit rates, false alarm rates and d' scores in the DLD and TD groups in the three rhythm conditions

\begin{tabular}{|c|c|c|c|c|c|c|c|c|c|}
\hline & & \multicolumn{4}{|c|}{ Hit rate } & \multicolumn{4}{|c|}{ False alarm rate } \\
\hline & & Baseline & \multicolumn{2}{|l|}{ Irregular } & Regular & \multicolumn{2}{|l|}{ Baseline } & Irregular & Regular \\
\hline DLD & & $0.61(0.24)$ & \multicolumn{2}{|l|}{$0.63(0.23)$} & $0.68(0.22)$ & $0.57(0.20)$ & & $0.52(0.27)$ & $0.52(0.27)$ \\
\hline \multirow{2}{*}{ TD } & \multicolumn{3}{|c|}{ Hit (z-score) } & \multicolumn{3}{|c|}{ False alarm (z-score) } & \multicolumn{3}{|l|}{$d^{\prime}$} \\
\hline & Baseline & Irregular & Regular & Baseline & Irregular & Regular & Baseline & Irregular & Regular \\
\hline TD & $0.97(0.56)$ & $0.86(0.61)$ & $0.90(0.70)$ & $-0.56(0.70)$ & $-0.57(0.43)$ & $-0.94(0.91)$ & $1.53(0.90)$ & $1.43(0.73)$ & $1.84(1.13)$ \\
\hline
\end{tabular}

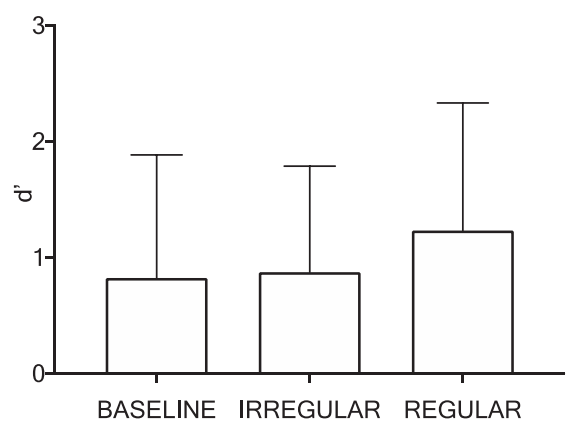

a)

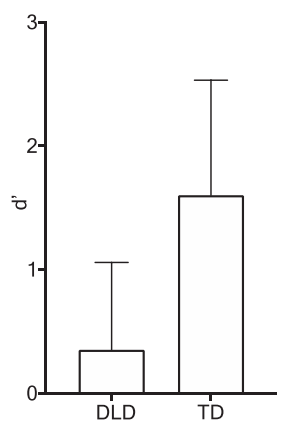

b)
FIG URE 2 (a) Performance on the grammaticality judgment task in the three rhythm conditions collapsed across TD and DLD groups. (b) Group difference in the grammaticality judgment task. Error bars represent standard deviations

measured by accuracy and reaction times for the three priming conditions. Stroop effects were calculated as the difference between mean reaction times for correct responses/accuracy in the incongruent and baseline conditions. Second, for testing the effect of rhythmic priming on the general performance on the task, accuracy and mean reaction times were calculated with collapsing across Stroop conditions for the three priming conditions. Trials with reaction times under $300 \mathrm{~ms}-$ $\mathrm{s}$ and above $5000 \mathrm{~ms}$-s were excluded from the analysis as these data resulted from technical errors or inattentiveness of the child, and are not meaningful.

\section{3 | RESULTS}

\subsection{Grammaticality judgment task}

Performance on the grammaticality judgment task is shown in Table 3 and Figure 2. We conducted a $2 \times 3$ ANOVA with Group as a betweensubject factor (DLD vs. TD) and Rhythm (Regular vs. Irregular vs. Baseline) as a within-subject factor.

The main effect of Group was significant $(F(1,32)=42.41, p<0.001)$ showing a significantly higher performance in children with TD (mean $d^{\prime}=1.60, S D=0.93$ ) than in children with DLD (mean $d^{\prime}=0.35$, $S D=0.71)$. The main effect of rhythm was also significant $(F(1$, $32)=3.15, p=0.0496$ ). Fisher's Least Significant Difference (LSD) post-hoc pairwise comparisons showed a significantly better performance in the regular (mean $d^{\prime}=1.23, S D=1.10$ ) than in the baseline (mean $d^{\prime}=0.82, S D=1.06 ; t(33)=2.117, p=0.025, d=0.38$ ) and irregular (mean $d^{\prime}=0.873, S D=0.91 ; t(33)=2.00, p=0.047, d=0.36$ ) conditions. There was no significant difference between the irregular and baseline conditions $(t(33)=0.327, p=0.779, d=0.05)$. The Group $X$ Rhythm interaction was not significant. To confirm the reliability of the significant effect of rhythm on grammaticality judgment, we also ran a Bayesian repeated measures ANOVA. This analysis also showed that the model with the main effect of rhythm and DLD is the best model of the data. The probability of the observed data was 42594 times greater with this model than the null model.

Since the DLD group showed a weak performance on the grammaticality judgment task, we tested whether d-prime scores on the three conditions significantly differ from chance level $\left(d^{\prime}=0\right)$ with a one-sample t-test in the TD and DLD groups, separately. We found that while children with TD showed a performance significantly above chance in each condition (baseline: $t(16)=7.012, p<0.001$, irregular $=t(16)=8.1, p<0.001$, regular: $t(16)=.6 .745, p<0.001)$, children with DLD performed above chance only in the regular rhythm condition (baseline: $t(16)=.715, p=0.485$, irregular $t(16)=1.786, p=0.093$, regular: $t(16)=3.897, p=0.001)$.

As Bedoin et al. (2016) argue, using silence as the baseline condition runs a risk that the effect of the previous prime persists and affects the performance in the silent baseline condition. To test this possibility, we grouped the responses of the baseline condition into three categories: (i) baseline block preceded by a regular block, (ii) baseline block preceded by an irregular block and (iii) baseline as the first block in the task. We calculated the mean d' scores for each category. We did not find a significant difference between these cases in a one-way ANOVA $\left(F(2,64)=1.452, p=0.242 ; M_{\text {irregular }}=0.97 M_{\text {regular }}=0.78 M_{\text {first }}=2.06\right)$. To investigate the possibility that the prime from the previous block only affected the first items of the block, we ran the same analyses only on the first five items from each block but no significant difference appeared between blocks in this analysis either $(F(2,64)=0.371$, $\left.p=0.692 ; M_{\text {irregular }}=1.46 M_{\text {regular }}=0.94 M_{\text {first }}=1.15\right)$. 
TAB LE 4 Mean naming times and standard deviations in milliseconds in the picture naming task

\begin{tabular}{|llll|}
\hline & Baseline & Irregular & Regular \\
\hline DLD & $1450(109)$ & $1328(86)$ & $1435(114)$ \\
\hline TD & $1183(101)$ & $1156(91)$ & $1192(81)$ \\
\hline
\end{tabular}

\subsection{Picture naming task}

Mean naming times in the picture naming task are shown in Table 4. Naming times for the correct answers were analyzed in a $2 \times 3$ ANOVA with Group (DLD vs. TD) as a between-subject factor and Rhythm (Regular vs. Irregular vs. Baseline) as a within-subject factor. The main effect of Group was marginally significant $(F(1,32)=4.14, p=0.050)$ reflecting slower naming times in the DLD ( $M=1404 \mathrm{~ms}, S D=422 \mathrm{~ms}$ ) than in the TD group ( $M=1177 \mathrm{~ms}, S D=370 \mathrm{~ms}$ ). There were no other significant effects or interactions.

\subsection{Non-verbal Stroop task}

Differences in Stroop effects depending on the priming condition were analyzed both measured by accuracy and reaction times as the dependent variable with $2 \times 3$ ANOVA-s with Group (DLD vs. TD) as a between-subject factor and Rhythm (Regular vs. Irregular vs. Baseline) as a within-subject factor (see a summary of Stroop scores in Table 5). The interaction between Group and Rhythm was significant in the case of reaction times $(F(2,64)=4.23, p=0.019)$. Fisher's Least Significant Difference (LSD) post-hoc pairwise comparisons showed a significantly smaller Stroop effect in the case of the irregular than in the baseline $(t(16)=2.53, p=0.010)$ and in the regular $(t(16)=2.53, p=0.020)$ condition in the TD group but no significant differences appeared in the DLD group. No other main effects or interactions were significant in the case of Stroop effects measured by reaction times or accuracy rates.

To explore whether rhythm had an effect on task performance in general, independently of the Stroop effect, accuracy and reaction times of correct responses collapsed across Stroop conditions were analyzed with $2 \times 3$ ANOVA-s with Group (DLD vs. TD) as a betweensubject factor and Rhythm (Regular vs. Irregular vs. Baseline) as a within-subject factor (see a summary of scores in Table 6). No main effects or interactions were found to be significant either for accuracy, or for reaction times.

\section{4 | DISCUSSION}

In the current study, we investigated the rhythmic priming effect in Hungarian-speaking 5-7-year-old children with and without DLD. Following exposure to a regular versus an irregular rhythm or no prime, children showed a rhythmic priming effect, that is, better performance, on a grammaticality judgment task, but did not show a rhythmic priming effect on two tasks requiring no grammatical processing: a picture naming task and a non-verbal Stroop task. The results indicate that a rhythm with a regular metrical structure facilitates subsequent grammatical processing in an agglutinating language, a morphosyntactic type not yet explored within this type of paradigm. The presence of the effect did not depend on the presence or absence of DLD. Children with DLD also benefitted from the regular rhythmic prime, suggesting that rhythmic training or the use of rhythmic stimuli during traditional language therapy might facilitate language processing in this atypical group.

Our finding on the presence of the rhythmic priming effect in a grammaticality judgment task in children with and without DLD is in line with previous studies finding better performance when children are exposed to a regular rhythm compared to an irregular one (Chern et al., 2018; Przybylski et al., 2013) or no rhythm at all (Bedoin et al., 2016). Our study also extends previous research by showing evidence for a longer effect of priming than previous studies as in the current study, children were presented with 10 sentences after the prime in the grammaticality judgment task that is slightly more than in previous studies in that six sentences were presented per block.

Regarding the difference between the baseline and irregular conditions in the grammaticality judgment task, we expected to find a weaker performance in the irregular condition than in the baseline condition based on Bedoin et al.'s (2016) observation of the rhythmic priming effect being stronger when comparing the regular condition to an irregular condition, than when comparing the regular condition to a non-rhythmic baseline. In the current study, we were able to directly compare the irregular and baseline conditions and found no significant difference between them. This suggests that irregular rhythm does not have a negative effect on subsequent grammatical processing. We note, however, that while Bedoin et al. (2016) used environmental noise as a baseline condition, we used silence; perhaps environmental noise and silence impact performance differently.

Using silence as the baseline condition runs a risk that the effect of the previous prime persists and affects the performance in the baseline condition. To investigate if the effect of the regular and irregular primes persisted until the presentation of the sentences in the baseline

TA B LE 5 Mean Stroop effects (difference between mean reaction times for the baseline and incongruent conditions) in the non-verbal Stroop tasks

\begin{tabular}{|c|c|c|c|c|c|c|}
\hline & \multicolumn{3}{|c|}{ Mean Stroop effect reaction time } & \multicolumn{3}{|c|}{ Mean Stroop effect accuracy rate } \\
\hline & Baseline & Irregular & Regular & Baseline & Irregular & Regular \\
\hline DLD & $213(282)$ & $324(231)$ & $288(345)$ & $0.04(0.13)$ & $0.11(0.10)$ & $0.07(0.08)$ \\
\hline
\end{tabular}

Reaction time data are reported in milliseconds. 
TAB LE 6 Mean reaction times and standard deviations in the non-verbal Stroop task. Reaction time data are reported in milliseconds

\begin{tabular}{|c|c|c|c|c|c|c|}
\hline & \multicolumn{3}{|c|}{ Mean reaction time } & \multicolumn{3}{|c|}{ Mean accuracy rate } \\
\hline & Baseline & Irregular & Regular & Baseline & Irregular & Regular \\
\hline DLD & $1434(280)$ & $1437(355)$ & 1455 (329) & $0.93(0.09)$ & $0.93(0.09)$ & $0.94(0.07)$ \\
\hline
\end{tabular}

condition, we calculated the grammaticality judgment performance in the baseline condition for (1) blocks preceded by a regular block, (2) blocks preceded by an irregular block and (3) blocks presented as the first block in the task. Grammaticality judgment performance did not show a significant difference between these three types of baseline blocks, suggesting that regular/irregular primes did not affect grammaticality judgment performance in subsequent baseline blocks. This pattern of results suggests that the effect of rhythmic stimulation is long enough to affect grammaticality judgments on the ten sentences immediately following the rhythm but fades away by the time the child is presented with the sentences in the subsequent block. Our procedures do not allow us to calculate the exact duration of the effect of the rhythmic stimulation because children took breaks of different lengths between blocks, but these results suggest that priming is not present for more than a few minutes.

The presence of the rhythmic priming effect in the grammaticality judgment task and its absence in the non-verbal Stroop task, a nonlinguistic task strongly relying on attentional processes, is in line with previous results (Chern et al., 2018). In the current study, the length of the blocks as well as the task procedures were closely matched between the three tasks. These results suggest that the rhythmic priming effect is specific to speech/language processing or to grammar processing. Note that in the non-verbal Stroop task, children with TD showed a reduced Stroop effect in the irregular condition compared to the baseline or regular conditions. This result could be explained by the fact that the Stroop effect in the irregular condition was negative in seven out of the seventeen children with TD, meaning that it took longer for them to respond to baseline trials than to Stroop trials. Lack of Stroop effects in the irregular condition in some children with TD motivates further research focusing on the effect of rhythmic priming on inhibition, but we believe that this result is not relevant for the main question of the current study, therefore we do not discuss it further.

To our knowledge, our study is the first one exploring the effect of rhythmic priming on word retrieval. The lack of rhythmic priming in the picture naming task suggests that the rhythmic priming effect is not only specific to the language domain but seems to be restricted to language perception or grammar. These results are in line with a recent study (Canette et al., 2020) testing the effect of a rhythmical music versus textural sounds on a semantic evocation task in which children were asked to verbalize concepts that were evoked by rhythmic music or sound texture. The study found that children produced more concepts after the textural sounds, suggesting that rhythmic priming did not facilitate semantic evocation. Although picture naming and semantic evocation measure partly different abilities, both involve lexical processes. The lack of rhythmic priming in lexical tasks further confirms that rhythmic priming is specific to grammar or receptive language skills.

The design of the current study did not enable us to decide which aspect of language processing-lower-level auditory processing of phonemes and syllables, the processing of higher-level linguistic structures or both-is facilitated by the regular prime, neither to explore the underlying mechanisms. The result that rhythmic priming facilitates phonological processing (Cason et al., 2015; Cason \& Schön, 2012) supports the role of auditory processing, but future studies need to find out whether improved grammatical processing is accounted for by better auditory processing in itself, or if rhythmic priming facilitates both auditory processing and grammatical processing.

The mechanisms underlying rhythmic priming are also still to be discovered. While musical rhythm and linguistic syntax certainly engage partially separate brain networks, a recent $\mathrm{AMRI}$ meta-analysis identified several overlapping brain regions (left IFG, left SMA, and bilateral insula) recruited both by rhythm and syntactic tasks (Heard \& Lee, 2020). Thus, activation of rhythm networks could affect subsequent syntactic processing through these particular brain regions. It is also possible that facilitation of temporal attention during the perception of rhythmic primes affects sequencing during speech perception, leading to more efficient detection of errors (see Bedoin et al., 2016; Kotz et al., 2009; Przybylski et al., 2013). More broadly, evidence for enhancement of neural processing during rhythmic priming comes from EEG data showing a relationship between entrainment effects during the primes and linguistic targets (Falk et al., 2017).

It is important to emphasize that a grammaticality judgment task requires strong metalinguistic skills, that makes it a less direct measure of grammatical processing than other measures of grammatical skills (e.g., sentence comprehension tasks in which participants have to choose the picture corresponding to the sentence among multiple options). While good grammatical skills are obviously necessary to detect grammatical errors, they are not sufficient. As language processes are highly automatic, it is possible that one has good grammatical skills and is able to process sentences but is less successful at detecting errors that requires metalinguistic skills and attention to violations. In this case, their performance will show a high hit rate with a relatively high false alarm rate. High false alarm rates played a stronger role in low d'-s than low hit rates, especially in the DLD group, meaning that judging ungrammatical sentences "correct" accounted for more errors than judging grammatical sentences "incorrect". This could mean that metalinguistic skills, attentional problems or the usual "yes"-bias commonly found in children also played a role in the performance on the grammaticality judgment task. Future studies in children with DLD will need to investigate the effect of rhythmic priming on grammatical 
processing using other behavioral tasks that tap into expressive and receptive morpho-syntactic ability, and would also benefit from using EEG to measure on-line grammatical processing, complementing work in adults (Canette et al., 2020; Kotz et al., 2005; Kotz \& Gunter, 2015).

Documenting effects on rhythmic priming in various languages and tasks could also help design ways to use rhythm in general (see also Schön \& Tillman, 2015), or rhythmic priming in particular (Bedoin et al., 2018) efficiently in speech-language therapy. Further rhythmic priming studies that manipulate the rhythm and the target task and measure brain activity during both the rhythmic priming stimuli and the presentation of the linguistic stimuli will help researchers to identify the therapeutical contexts within which rhythm training could be used to facilitate language comprehension or production. If future research ends up supporting the benefits of the use of rhythmic stimuli during speechlanguage therapy, then rhythmic training or presentation of rhythmic stimuli during tasks targeting speech-language skills can eventually be incorporated directly into clinical practice.

\section{ACKNOWLEDGMENTS}

This study was conducted with the support of the European Union's Horizon 2020 research and innovation program under the Marie Sklodowska-Curie grant agreement No. 641858 (PredictAble project) to J.G and E.L, the ERC Consolidator Grant (773202 ERC-2017-COG 'BabyRhythm'; https://erc.europa.eu/funding/consolidator-grants) to J.G. Á.L. was supported by the Momentum Research Grant of the Hungarian Academy of Sciences (Momentum 96233 MTA-BME Momentum Language Acquisition Research Group). E.L. was also supported by funding from the National Institutes of Health: the NIH Common Fund through the Office of NIH Director, and the National Institute on Deafness and Other Communication Disorders, under Award Numbers DP2HD098859 and R01DC016977. The content is solely the responsibility of the authors and does not necessarily represent the official views of the NIH. The authors declare no conflicts of interest with regard to the funding source for this study.

Special thanks go to the children, their teachers and parents for their kindness and cooperation. We thank Ágnes Kovács for her inevitable help in screening our participants and Lilla Zakariás for her help in recording the stimuli and helpful advices about task procedures. We thank Dr. Reyna Gordon for her invaluable suggestions for the manuscript and huge thanks go to the Music Cognition Lab of Vanderbilt University Medical Center, Nashville for the fruitful discussions and motivating environment.

\section{DATA AVAILABILITY STATEMENT}

The data that support the findings of this study are available from the corresponding author upon reasonable request from Eniko Ladanyi at the following email address: enikoladanyi@gmail.com.

\section{REFERENCES}

American Speech-Language-Hearing Association. (2005). Evidence-based practice in communication disorders.

Bates, E., D’Amico, S., Jacobsen, T., Székely, A., Andonova, E., Devescovi, A., Herron D., Lu C. C., Pechmann T., Pléh C., Wicha N., Federmeier K., Gerd- jikova I., Gutierrez G., Hung D., Hsu J., Iyer G., Kohnert K., Mehotcheva T., ... Tzeng O. (2003). Timed picture naming in seven languages. Psychonomic Bulletin \& Review, 10, 344-380.

Bedoin, N., Besombes, A. M., Escande, E., Dumont, A., Lalitte, P., \& Tillmann, B. (2018). Boosting syntax training with temporally regular musical primes in children with cochlear implants. Annals of Physical and Rehabilitation Medicine, 61(6), 365-371.

Bedoin, N., Brisseau, L., Molinier, P., Roch, D., \& Tillmann, B. (2016). Temporally regular musical primes facilitate subsequent syntax processing in children with specific language impairment. Frontiers in Neuroscience, 10, 245. https://doi.org/10.3389/fnins.2016.00245

Bishop, D. V. M. (1983). Test For Reception of Grammar. Manchester, United Kingdom: Medical Research Council.

Bishop, D. V. M. (2012). TROG-Test For Reception Of Grammar Handbook. Budapest, Hungary: OS Hungary Tesztfejlesztő Kft.

Bishop, D. V. M., Snowling, M. J., Thompson, P. A., \& Greenhalgh, T.; the CATALISE-2 Consortium. (2017). Phase 2 of CATALISE: A multinational and multidisciplinary Delphi consensus study of problems with language development: Terminology. Journal of Child Psychology and Psychiatry, and Allied Disciplines, 58(10), 1068-1080. https://doi.org/10.1111/jcpp. 12721

Canette, L.-H., Fiveash, A., Krzonowski, J., Corneyllie, A., Lalitte, P., Thompson, D., Trainor, L., Bedoin, N., \& Tillmann, B. (2020). Regular rhythmic primes boost $\mathrm{P} 600$ in grammatical error processing in dyslexic adults and matched controls. Neuropsychologia, 138. https://doi.org/10.1016/j. neuropsychologia.2019.107324

Canette, L. H., Lalitte, P., Bedoin, N., Pineau, M., Bigand, E., \& Tillmann, B. (2020). Rhythmic and textural musical sequences differently influence syntax and semantic processing in children. Journal of Experimental Child Psychology, 191, 104711. https://doi.org/10.1016/j.jecp.2019.104711

Cason, N., \& Schön, D. (2012). Rhythmic priming enhances the phonological processing of speech. Neuropsychologia, 50(11), 2652-2658. https://doi. org/10.1016/j.neuropsychologia.2012.07.018

Cason, N., Astésano, C., \& Schön, D. (2015). Bridging music and speech rhythm: Rhythmic priming and audio-motor training affect speech perception. Acta Psychologica, 155(0), 43-50. https://doi.org/10.1016/j. actpsy.2014.12.002

Chern, A., Tillmann, B., Vaughan, C., \& Gordon, R. L. (2018). New evidence of a rhythmic priming effect that enhances grammaticality judgments in children. Journal of Experimental Child Psychology, 173, 371-379. https: //doi.org/10.1016/j.jecp.2018.04.007

Clahsen, H. (1999). Lexical entries and rules of language: A multidisciplinary study of German inflection. Behavioral and Brain Sciences, 22, 991-1013. https://doi.org/10.1017/S0140525X99002228

Conti-Ramsden, G., Durkin, K., Toseeb, U., Botting, N., \& Pickles, A. (2018). Education and employment outcomes of young adults with a history of developmental language disorder. International Journal of Language \& Communication Disorders, 53(2), 237-255.

Corriveau, K. H., \& Goswami, U. (2009). Rhythmic motor entrainment in children with speech and language impairments: Tapping to the beat. Cortex; A Journal Devoted to the Study of the Nervous System and Behavior, 45(1), 119-130. https://doi.org/10.1016/j.cortex.2007.09.008

Corriveau, K., Pasquini, E., \& Goswami, U. (2007). Basic auditory processing skills and specific language impairment: A new look at an old hypothesis. Journal of Speech, Language, and Hearing Research, 50(3), 647-666. https: //doi.org/10.1044/1092-4388(2007/046

Csányi, F. I. (1974). Peabody Szókincs-Teszt. Budapest, Hungary: Bárczi Gusztáv Gyógypedagógiai Fõiskola.

Cumming, R., Wilson, A., Leong, V., Colling, L. J., \& Goswami, U. (2015). Awareness of rhythm patterns in speech and music in children with specific language impairments. Frontiers in Human Neuroscience, 9, 672. https: //doi.org/10.3389/fnhum.2015.00672

Cummings, A., Seddoh, A., \& Jallo, B. (2016). Phonological code retrieval during picture naming: Influence of consonant class. Brain Research, 1635, 71-85. https://doi.org/10.1016/j.brainres.2016.01.014 
Falk, S., Lanzilotti, C., \& Schön, D. (2017). Tuning neural phase entrainment to speech. Journal of cognitive neuroscience, 29(8), 1378-1389. https:// doi.org/10.1162/jocn_a_01136

Fiveash, A., Bedoin, N., Lalitte, P., \& Tillmann, B. (2020). Rhythmic priming of grammaticality judgements in children: Duration matters. Journal of Experimental Child Psychology, 197, 104885. https://doi.org/10.1016/j. jecp.2020.104885

Gathercole, S. E., \& Baddeley, A. D. (1990). Phonological memory deficits in language disordered children: Is there a causal connection? Journal of Memory and Language, 29, 336-360. https://doi.org/10.1016/ 0749-596X(90)90004-J

Gopnik, M., \& Crago, M. B. (1991). Familial aggregation of a developmental language disorder. Cognition, 39, 1-50. https://doi.org/10.1016/ 0010-0277(91)90058-C

Gordon, R. L., Jacobs, M. S., Schuele, C. M., \& Mcauley, J. D. (2015). Perspectives on the rhythm-grammar link and its implications for typical and atypical language development. Annals of the New York Academy of Sciences, 1337(1), 16-25. https://doi.org/10.1111/nyas.12683

Gordon, R. L., Shivers, C. M., Wieland, E. A., Kotz, S. A., Yoder, P. J., \& Mcauley D., J. (2015). Musical rhythm discrimination explains individual differences in grammar skills in children. Developmental Science, 18(4), 635644. https://doi.org/10.1111/desc.12230

Goswami, U. (2011). A temporal sampling framework for developmental dyslexia. Trends in Cognitive Sciences, 15(1), 3-10. https://doi.org/10. 1016/j.tics.2010.10.001

Heard, M., \& Lee, Y. S. (2020). Shared neural resources of rhythm and syntax: An ALE meta-analysis. Neuropsychologia, 137, 107284. https://doi. org/10.1016/j.neuropsychologia.2019.107284

Hsu, H. J., \& Bishop, D. V. M. (2011). Grammatical difficulties in children with specific language impairment (SLI): Is learning deficient? Human Development, 53, 264-277. https://doi.org/10.1159/000321289

Kas, B., \& Lukács, Á. (2008). A magyar vonatkozó mellékmondatok megértése tipikus és zavart nyelvi fejloésben [The comprehension of Hungarian relative clauses in typical development and in children with specific language impairment]. In: (Pléh Cs. Ed.): A fejlódési plaszticitás és idegrendszer [Developmental plasticity and the nervous system] (pp. 51-86). Budapest: Akadémiai Kiadó. https://doi.org/10.1556/mpszle.63.2008.1. 5

Kas, B., \& Lukács, Á. (in preparation). Magyar Mondatutánmondási Teszt.

Kotz, S. A., \& Gunter, T. C. (2015). Can rhythmic auditory cuing remediate language-related deficits in Parkinson's disease. Annals of the. New York Academy. Science, 1337, 62-68. https://doi.org/10.1111/ nyas. 12657

Kotz, S. A., Gunter, T. C., \& Wonneberger, S. (2005). The basal ganglia are receptive to rhythmic compensation during auditory syntactic processing: ERP patient data. Brain and Language, 95, 70-71. https://doi.org/10. 1016/j.bandl.2005.07.039

Kotz, S. A., \& Schwartze, M. (2010). Cortical speech processing unplugged: A timely subcortico-cortical framework. Trends in Cognitive Sciences, 14(9), 392-399. https://doi.org/10.1016/j.tics.2010.06.005

Kotz, S. A., Schwartze, M., \& Schmidt-Kassow, M. (2009). Non-motor basal ganglia functions: A review and proposal for a model of sensory predictability in auditory language perception. Cortex; A Journal Devoted to the Study of the Nervous System and Behavior, 45, 982-990. https://doi. org/10.1016/j.cortex.2009.02.010

Ladányi, E., Persici, V., Fiveash, A., Tillmann, B., \& Gordon, R. L. (2020). Is atypical rhythm a risk factor for developmental speech and language disorders? Wiley Interdisciplinary Reviews: Cognitive Science, e1528. https: //doi.org/10.1002/wcs.1528

Ladányi, E., \& Lukács, Á. (2016). Lexical Conflict Resolution in Children with Specific Language Impairment. Journal of Communication Disorders, 61, 119-130. https://doi.org/10.1016/j.jcomdis.2016.04.004

Lee, Y. S., Ahn, S., Holt, R. F., \& Schellenberg, E. G. (2020). Rhythm and syntax processing in school-age children. Developmental Psychology, 56(9), 1632-1641. https://doi.org/10.1037/dev0000969
Lely, H. K. J. v. d., \& Stollwerck, L. (1997). Binding theory and grammatical specific language impairment in children. Cognition, 62, 245-290. https: //doi.org/10.1016/S0010-0277(96)00783-4

Leonard, L. B., Lukács, Á., \& Kas, B. (2012). Tense and aspect in childhood language impairment: Contributions from Hungarian. Applied Psycholinguistics, 33, 305-328. https://doi.org/10.1017/S0142716411000361

Leonard, L. (1998). Children With Specific Language Impairment. Cambridge, MA: MIT Press 2014

Lukács, Á., Győri, M., \& Rózsa, S. (2012). A TROG pszichometriai jellemzőinek magyar vizsgálata, a normák kialakítása. In (D. V. M. Bishop Ed.), TROG-Test for reception of grammar handbook (pp. 47-86). Budapest, Hungary: OS Hungary Tesztfejlesztő Kft.

Lukács, Á., Leonard, L. B., Kas, B., \& Pléh, C.s. (2009). The use of tense and agreement by Hungarian-speaking children with language impairment. Journal of Speech, Language, and Hearing Research, 52, 98-117. https://doi. org/10.1044/1092-4388(2008/07-0183)

Mathôt, S., Schreij, D., \& Theeuwes, J. (2012). OpenSesame: An open-source, graphical experiment builder for the social sciences. Behavior Research Methods, 44(2), 314-324. https://doi.org/10.3758/s13428-011-0168-7

Marie, C., Magne, C., \& Besson, M. (2011). Musicians and the metric structure of words. Journal of Cognitive Neuroscience, 23, 294-305. https://doi. org/10.1162/jocn.2010.21413

Moritz, C., Yampolsky, S., Papadelis, G., Thomson, J. M., \& Wolf, M. (2013). Links between early rhythm skills, musical training, and phonological awareness. Reading and Writing, 26(5), 739-769. https://doi.org/10. 1007/s11145-012-9389-0

Muneaux, M., Ziegler, J. C., Truc, C., Thomson, J., \& Goswami, U. (2004). Deficits in beat perception and dyslexia: Evidence from French. Neuroreport, 15(8), 1255-1259. https://doi.org/10.1097/01.wnr.0000127459. 31232.c4

Overy, K., Nicolson, R. I., Fawcett, A. J., \& Clarke, E. F. (2003). Dyslexia and music: Measuring musical timing skills. Dyslexia, 9(1), 18-36. https://doi. org/10.1002/dys.233

Ozernov-Palchik, O., Wolf, M., \& Patel, A. D. (2018). Relationships between early literacy and nonlinguistic rhythmic processes in kindergarteners. Journal of Experimental Child Psychology, 167, 354-368. https://doi.org/ 10.1016/j.jecp.2017.11.009

Patel, A. D. (2014). The evolutionary biology of musical rhythm: Was Darwin wrong?. Plos Biology, 12(3), e1001821. https://doi.org/10.1371/journal. pbio.1001821

Przybylski, L., Bedoin, N., Krifi-Papoz, S., Herbillon, V., Roch, D., Léculier, L., Kotz, S. A., \& Tillmann, B. (2013). Rhythmic auditory stimulation influences syntactic processing in children with developmental language disorders. Neuropsychology, 27(1), 121-131. https://doi.org/10. 1037/a0031277

Racsmány, M., Lukács, Á., Németh, D., \& Pléh, C. (2005). A verbális munkamemória magyar nyelvű vizsgálóeljárásai. Magyar Pszichológiai Szemle, 60, 479-506. https://doi.org/10.1556/mpszle.60.2005.4.3

Raven, J., Court, J., \& Raven, J. (1987). Raven's Progressive Matrices And Raven's Colored Matrices. London, England: H. K. Lewis.

Rice, M. L., Wexler, K., \& Cleave, P. L. (1995). Specific language impairment as a period of optional infinitive. Journal of Speech, Language, and Hearing Research, 38, 850-863. https://doi.org/10.1044/jshr.3804.850

Rosenbaum, S., \& Simon, P. (2016). Committee on the Evaluation of the Supplemental Security Income (SSI) Disability Program for Children with Speech Disorders and Language Disorders, Board on the Health of Select Populations, Board on Children, Youth, and Families, Institute of Medicine, Division of Behavioral and Social Sciences and Education, \& National Academies of Sciences, Engineering, and Medicine (Eds.). Speech and Language Disorders in Children: Implications for the Social Security Administration's Supplemental Security Income Program. National Academies Press (US).

Schön, D., \& Tillmann, B. (2015). Short-and long-term rhythmic interventions: Perspectives for language rehabilitation. Annals of the New York Academy of Sciences, 1337, 32-39. https://doi.org/10.1111/nyas.12635 
Siptár, P., \& Törkenczy, M. (2000). The phonology of Hungarian. Oxford: Oxford University Press.

Tallal, P., \& Piercy, M. (1973). Defects of non-verbal auditory perception in children with developmental dysphasia. Nature, 241, 468-469. https:// doi.org/10.1038/241468a0

Tomblin, J. B., Records, N. L., Buckwalter, P., Zhang, X., Smith, E., \& O’Brien, M. (1997). Prevalence of specific language impairment in kindergarten children. Journal of Speech, Language, and Hearing Research, 40(6), 12451260. https://doi.org/10.1044/jslhr.4006.1245

Ullman, M. T., \& Pierpont, E. I. (2005). Specific language impairment is not specific to language: The procedural deficit hypothesis. Cortex; $A$ Journal Devoted to the Study of the Nervous System and Behavior, 41, 399433. https://doi.org/10.1016/S0010-9452(08)70276-4

Vinkler, Z., \& Pléh, C. (1995). A case of a specific language impaired child in Hungarian. In (M. Kovačevic' Ed.), Language And Language Communication Barriers (pp. 131-158). Zagreb: Hrvatska Sveucilisna Naklada.
Woodruff Carr, K., White-Schwoch, T., Tierney, A. T., Strait, D. L., \& Kraus, N. (2014). Beat synchronization predicts neural speech encoding and reading readiness in preschoolers. Proceedings of the National Academy of Sciences, 111(40), 14559-14564.

How to cite this article: Ladányi E, Lukács Á, Gervain J. Does rhythmic priming improve grammatical processing in Hungarian-speaking children with and without developmental language disorder? Developmental Science. 2021;24:e13112. https://doi.org/10.1111/desc.13112 